\title{
HEALTH POLICY \\ Public Mistrust of the U.S. Health Care System's Profit Motives: Mixed-Methods Results from a Randomized Controlled Trial
}

\author{
Jennifer Richmond, $M S P H^{1,2}$, Wizdom Powell, $P h D, M P H^{2,3,4}$, Maureen Maurer, $M P H^{7}$, \\ Rikki Mangrum, MLS', Marthe R. Gold, MD, MPH ${ }^{5}$, Ela Pathak-Sen, $M B A^{6}$, Manshu Yang, $P h D^{\prime}$, and \\ Kristin L. Carman, $\mathrm{PhD}^{7}$ \\ 'Domestic Research and Evaluation, American Institutes for Research, Chapel Hill, NC, USA; ${ }^{2}$ Department of Health Behavior, University of North \\ Carolina at Chapel Hill Gillings School of Global Public Health, Chapel Hill, NC, USA; ${ }^{3}$ Health Disparities Institute, UConn Health, University of \\ Connecticut, Hartford, CT, USA; ${ }^{4}$ Department of Psychiatry, UConn Health, University of Connecticut, Farmington, CT, USA; ${ }^{5} \mathrm{New}$ York Academy of \\ Medicine, New York, NY, USA; ${ }^{6}$ Commotion, Painswick Stroud, UK; ${ }^{7}$ Patient-Centered Outcomes Research Institute, Washington, DC, USA.
}

BACKGROUND: Decision makers are increasingly tasked with reducing health care costs, but the public may be mistrustful of these efforts. Public deliberation helps gather input on these types of issues by convening a group of diverse individuals to learn about and discuss valuesbased dilemmas.

OBJECTIVE: To explore public perceptions of health care costs and how they intersect with medical mistrust.

DESIGN AND PARTICIPANTS: This mixed-methods study analyzed data from a randomized controlled trial including four public deliberation groups $(n=96)$ and a control group ( $n=348$ ) comprising English-speaking adults aged 18 years and older. Data were collected in 2012 in four U.S. regions.

APPROACH: We used data from four survey items to compare attitude shifts about costs among participants in deliberation groups to participants in the control group. We qualitatively analyzed deliberation transcripts to identify themes related to attitude shifts and to provide context for quantitative results about attitude shifts.

KEY RESULTS: Deliberation participants were significantly more likely than control group participants to agree that doctors and patients should consider cost when making treatment decisions $(\beta=0.59 ; p<0.01)$ and that people should consider the effect on group premiums when making treatment decisions ( $\beta=0.48 ; p<0.01)$. Qualitatively, participants mistrusted the health care system's profit motives (e.g., that systems prioritize making money over patient needs); however, after grappling with patient/doctor autonomy and learning about and examining their own views related to costs during the process of deliberation, they largely concluded that payers have the right to set some boundaries to curb costs.

CONCLUSIONS: Individuals who are informed about costs may be receptive to boundaries that reduce societal health care costs, despite their mistrust of the health care system's profit motives, especially if decision makers communicate their rationale in a transparent manner. Future work should aim to develop transparent policies and practices that earn public trust.

Received March 15, 2017

Revised August 3, 2017

Accepted August 17, 2017

Published online September 5, 2017
KEYWORDS: health care costs; decision-making; health services research; patient engagement; comparative effectiveness. J Gen Intern Med 32(12): 1396-402

DOI: $10.1007 / \mathrm{s} 11606-017-4172-1$

(C) Society of General Internal Medicine 2017

\section{INTRODUCTION}

In the United States, health care spending accounts for almost $18 \%$ of the gross domestic product; however, approximately $20 \%$ of health care expenditures may constitute wasteful spending (e.g., money spent on unnecessary medical treatments). ${ }^{1}$ Efforts to reduce spending may be hindered by public mistrust of the health care system and its motives for reducing costs. $^{2,3}$ Medical mistrust - or suspicion of health care providers, organizations, and/or systems - is also associated with several health-related outcomes, such as delaying or avoiding seeking health care and poor self-reported health status. ${ }^{2,4-6}$ Such mistrust may be heightened as our nation debates the health and economic costs associated with the potential repeal of the Affordable Care Act. Therefore, it seems particularly important for decision-makers to consider controlling costs without further eroding public trust.

Given the need to address public perceptions and trust, patient advocates argue for including public input in policy decisions that set health care priorities. ${ }^{7}$ Public deliberation is one participatory approach for gathering this input by obtaining informed views on values-laden topics. In public deliberation, a sponsor convenes a group of individuals of diverse backgrounds (e.g., sociodemographic, geographic) to provide informed input regarding complex issues that lack simple technical solutions. ${ }^{8}$ Participants learn about controversial topics and receive balanced information, typically through educational materials or interactions with experts. ${ }^{9}$ Participants are encouraged to learn from others, explain their perspectives, and examine their views as they work toward a solution that benefits the larger community.

Little is known about the effect of public deliberation on participants' attitudes about health care costs or how public perceptions of cost intersect with medical mistrust. We used 
public deliberation data to explore these gaps. Our research questions were as follows:

1. Do attitudes about health care costs shift after deliberation when compared to a control group?

2. What are public perspectives about health care costs?

3. How does the public describe the influence of costs on individual and societal health care decision-making?

4. How does medical mistrust relate to individuals' descriptions of health care costs and how these costs influence decision-making?

\section{METHODS}

We used data from a randomized controlled trial (RCT) designed to assess the effectiveness of public deliberation and to understand public perceptions about the use of an evidencebased approach in health care decision-making. In the RCT, participants were assigned to a control group or one of four distinct deliberative methods that varied in the number of participants, session length, interaction mode (online or inperson), and use of experts. Details about each deliberative method and the larger study are reported elsewhere. ${ }^{9-13}$

For this study, we analyzed data obtained through one deliberative method, Citizens' Panel (CP), which was the method with the longest duration, comprising a total of $20 \mathrm{~h}$ over 2.5 days. The other deliberative methods were significantly shorter (ranging from 2 to $6 \mathrm{~h}$ ), and primarily involved participant deliberation about the use of evidence regarding medical effectiveness in decision-making. The additional length of the CP method afforded participants a greater opportunity for substantive discussion on costs in the context of evidence-based decision-making regarding health care, as described below. Therefore, we analyzed the CP sessions to explore participants' views on health care costs.

We conducted four CP sessions from August through November 2012 in Chicago, Illinois; Sacramento, California; Silver Spring, Maryland; and Durham, North Carolina. We selected these locations to achieve racial/ethnic, socioeconomic, and geographic diversity. For example, Chicago and Silver Spring are large urban areas with diverse ethnic minority populations. Durham and Sacramento are moderate-sized cities surrounded by rural areas within easy driving distance, which increased access to suburban and rural residents.

After receiving institutional review board approval, we recruited participants via local recruitment firms who used their databases to contact a sample of eligible individuals reflecting the city's population distribution by gender, African-American race, Hispanic ethnicity, and age, according to the U.S. Census. Participants were 18 years of age or older, were comfortable reading and conversing in English, and had never worked as health care professionals. Participants were required to have access to the internet because two deliberative methods in the larger study required online participation. CP and control group participants received written materials about quality care, medical evidence, comparative effectiveness research, and health care costs. We conducted three rounds of consumer interviews (9-12 people per round) to test user understanding of written materials and whether they were perceived as unbiased. CP participants discussed information in the materials among one another, whereas control group participants read the materials themselves. Facilitators also received a 2-day training about topics such as encouraging equal participation and opposing viewpoints and eliciting participant values while remaining impartial. ${ }^{9,14}$

We posed the following deliberative question to $\mathrm{CP}$ participants: "Should individual patients and/or their doctors be able to make any health decisions, no matter what the evidence of medical effectiveness shows, or should society ever specify some boundaries for these decisions?" While grappling with this question, participants interacted with and asked questions of experts at key points during deliberation. Experts provided up-to-date background information so that participants had a common understanding of the issues, and offered different perspectives on content areas to familiarize participants with multiple sides of a controversy.

Cost discussions arose in a number of ways. For example, educational materials included information about rising costs and who pays for health care. Experts presented information about U.S. health care costs compared to other nations and described cost drivers. Experts also explained that treatment costs vary widely, even within the same community.

\section{Data Analysis}

Informed by a directed content analysis approach, we first analyzed quantitative data regarding shifts in attitude after deliberation and subsequently analyzed qualitative data from participant discussions to explore contextual factors arising during deliberation that helped explain quantitative results. ${ }^{15}$ First, we answered research question 1 with quantitative data from a pre- and post-deliberation survey that compared costrelated changes in attitude among CP and control group participants. Participants completed the pre-survey before receiving educational materials and completed the post-survey about 2 weeks after deliberation. Control group participants completed surveys at the same time as deliberation participants in each location. To better understand attitudes about costs in medical decision-making, we analyzed four questions that explored this area. Three items assessed attitudes toward considering cost when making treatment decisions; the fourth item measured attitudes regarding whether individuals should consider how their decisions affect others in their insurance plan (Table 1). We calculated a summary score for the first three items by averaging responses across those items; the fourth item was considered a separate outcome. ${ }^{9}$ Items were measured on a five-point Likert scale ranging from "disagree strongly" to "agree strongly." We reverse-coded items so that 
Table 1 Outcome Measures for Cost Considerations in Health Care Decision-Making

Survey Question

Summary Score: Doctors and patients should consider cost evidence when making treatment decisions*

Q1. People should be able to get any medical treatment, no matter how much the treatment costs.

Q2. Doctors should be able to provide any medical treatment, no matter how much the treatment costs.

Q3. For health problems that are not life-threatening, doctors should be able to recommend any medical treatment, no matter how much the treatment costs.

Q4. People with health insurance should consider the effect of their treatment decisions on the cost of health insurance premiums for everyone in their health plan.

*The three items showed good internal consistency reliability with Cronbach's alpha of 0.87

higher scores indicated stronger agreement that costs should be considered in decision-making. We used analysis of covariance (ANCOVA) to compare mean pre-post outcome changes between the CP groups and control group, while controlling for the following covariates, using SAS version 9.2 software (SAS Institute Inc., Cary, NC, USA): pre-survey outcome scores, overall health status, health care system experience, gender, age, marital status, education, employment status, bilingual status, and geographic location.

Next, we used qualitative analysis to answer research questions $2-4$. CP group discussions were audio- and videorecorded and professionally transcribed. Qualitative data were analyzed by the first author, with input from a larger team of eight researchers. This team included medical mistrust and qualitative analysis experts, researchers who contributed to the original study design, and individuals who facilitated $\mathrm{CP}$ groups. To develop the codebook, we reviewed field notes written immediately after the $\mathrm{CP}$ sessions and transcripts to note initial concepts that arose repeatedly throughout discussions. ${ }^{16}$ This process resulted in 13 codes (e.g., cost drivers and trust/mistrust of the health care system). Each transcript was coded using NVivo version 11 software. After coding the transcripts, the first author wrote memos to summarize topical themes - by looking for patterns and describing relationships between concepts - and to describe how these themes related to quantitative results. ${ }^{16,17}$ The NVivo query function was also used to analyze output for each code by race/ethnicity to explore whether there were key differences in patterns by race/ethnicity. Lastly, the first author reread the transcripts to test findings and identify exceptions to and alternative explanations for themes. ${ }^{18}$

\section{RESULTS}

\section{Sample Description}

Ninety-six individuals participated in $\mathrm{CP}$ groups and completed pre- and post-surveys; a range of 21-28 people participated in each CP group. The control group included 348 individuals. Randomization resulted in an approximately equal distribution of participants in each deliberative method but a different proportion of participants in control and $\mathrm{CP}$ groups with specific incomes and racial/ethnic backgrounds. In the larger study, we also found insurance status differences between CP and control groups. Therefore, we weighted participants to the U.S. Census population distribution with regard to income, race/ethnicity, and insurance status, and used the weights in ANCOVA analyses. ${ }^{9}$ Table 2 presents participant demographics.

\section{Survey Results: Attitude Shifts}

When compared to the control group, $\mathrm{CP}$ participation was associated with a 0.59 -unit greater increase on the five-point Likert scale toward agreement that doctors and patients should consider cost when making treatment decisions $(\beta=0.59$, $p<0.01$ ). Similarly, CP participation was associated with a 0.48 -unit greater increase on the five-point Likert scale toward

Table 2 Participant Demographic Characteristics*

\begin{tabular}{|c|c|c|}
\hline Characteristic & $\begin{array}{l}\text { Citizen } \\
\text { Panel } \\
(n=96)\end{array}$ & $\begin{array}{l}\text { Control } \\
(n=348)\end{array}$ \\
\hline \multicolumn{3}{|l|}{ Gender } \\
\hline Female & $55(57 \%)$ & $196(56 \%)$ \\
\hline \multicolumn{3}{|l|}{ Age } \\
\hline Under 65 years & $83(86 \%)$ & $308(89 \%)$ \\
\hline 65 years and over & $13(14 \%)$ & $40(11 \%)$ \\
\hline \multicolumn{3}{|l|}{ Race/ethnicity } \\
\hline White & $47(49 \%)$ & $252(72 \%)$ \\
\hline Black or African American & $43(45 \%)$ & $75(22 \%)$ \\
\hline Other race & $6(6 \%)$ & $21(6 \%)$ \\
\hline Hispanic (any race) & $10(10 \%)$ & $17(5 \%)$ \\
\hline \multicolumn{3}{|l|}{ Bilingual status } \\
\hline Speaks language other than & $6(6 \%)$ & $26(8 \%)$ \\
\hline \multicolumn{3}{|l|}{ English at home } \\
\hline \multicolumn{3}{|l|}{ Education ${ }^{\dagger}$} \\
\hline High school or less & $22(24 \%)$ & $41(12 \%)$ \\
\hline Some college or two-year degree & $34(37 \%)$ & $107(32 \%)$ \\
\hline Four-year college degree or higher & $35(39 \%)$ & $189(56 \%)$ \\
\hline \multicolumn{3}{|l|}{ Employment status } \\
\hline Employed & $56(58 \%)$ & $231(66 \%)$ \\
\hline Unemployed & $19(20 \%$ & $62(18 \%)$ \\
\hline \multirow{2}{*}{\multicolumn{3}{|c|}{ Marital status }} \\
\hline & & \\
\hline Never married & $27(28 \%)$ & $87(25 \%)$ \\
\hline Married or living with a partner & $55(57 \%)$ & $203(58 \%)$ \\
\hline Separated, divorced, or widowed & $14(15 \%)$ & $58(17 \%)$ \\
\hline \multicolumn{3}{|l|}{ Self-rated health status } \\
\hline Excellent, very good, or good & $80(83 \%)$ & $303(87 \%)$ \\
\hline Fair or poor & $16(17 \%)$ & $45(13 \%)$ \\
\hline \multicolumn{3}{|l|}{ Health care system experience } \\
\hline $\begin{array}{l}\text { Has seen a doctor three or more times } \\
\text { in past } 12 \text { months for same condition }\end{array}$ & $39(41 \%)$ & $110(32 \%)$ \\
\hline $\begin{array}{l}\text { Has a close friend or family member } \\
\text { who has seen a doctor three or more } \\
\text { times in past } 12 \text { months for same } \\
\text { condition }\end{array}$ & $61(64 \%)$ & $201(58 \%)$ \\
\hline \multicolumn{3}{|l|}{ Health insurance status } \\
\hline Insured & $71(74 \%)$ & $260(75 \%)$ \\
\hline \multicolumn{3}{|l|}{ Income (annual) } \\
\hline$\$ 29,999$ or less & $19(20 \%)$ & $57(16 \%)$ \\
\hline$\$ 30,000$ to $\$ 59,999$ & $35(36 \%)$ & $90(26 \%)$ \\
\hline$\$ 60,000$ to $\$ 100,000$ & $28(29 \%)$ & $103(30 \%)$ \\
\hline More than $\$ 100,000$ & $14(15 \%)$ & $98(28 \%)$ \\
\hline
\end{tabular}

*Demographic characteristics are presented for participants who completed both the pre- and post-survey

Among participants aged 25 and older

${ }^{*}$ Not including pregnancy 
agreement that people should consider group premium effects when making treatment decisions $(\beta=0.48, p<0.01)$. Table 3 summarizes these results.

\section{Context for Attitude Shifts: Qualitative Themes Regarding Cost}

Below, we describe themes related to health care costs that emerged from discussions, which provide context about how attitudes may have shifted. Themes were generally consistent across race/ethnicity; however, two notable exceptions are described below.

Reactions to Cost Information. Initially, participants reacted with confusion to information presented in educational materials and by experts regarding variation in health care prices and rising costs. One participant asked, "If it's the same test, why wouldn't it cost the same depending on where you're going?" Participants also asked whether the U.S. population was healthier or received better care than other countries, since the U.S. spends so much on health care. As experts explained that the U.S. is not a world leader in health outcomes, participants at times questioned the evidence from which these conclusions were drawn. One participant wondered, "can we trust [the evidence]?... Evidence can be manipulated."

Perceived Financial Motives Connected to Mistrust. Across all deliberation groups, participants expressed mistrust of the health care system and worried that it prioritized financial returns over patient health. One participant noted, "I can't trust the private companies and private industries to do what is in my best interest, because there's some criminals in there that... are just trying to get as much money as possible...." Additionally, participants thought that pharmaceutical companies pushed expensive drugs and offered doctors incentives for prescribing costly medicines even if they were suboptimal. One participant noted, "You still have to consider the roles that the pharmaceutical [companies] play as far as the cost being high... just the way that they push stuff and pay the doctors under the table."

Although participants were generally suspicious of doctors' profit motives, others pushed back and described having trust in doctors: "I think we have to trust doctors a little bit too... I hear a lot of [people saying] doctors are out to get money... I adore my doctor." Similarly, other participants blamed the health care system rather than individual doctors for overuse of medical procedures, because "you've got to fill this bed."

Both African-American and White participants expressed mistrust of the health care system's profit motives. However, African-American participants commonly expressed mistrust by describing personal experiences, whereas White participants largely spoke in general terms about profit motives. For example, a White participant explained pharmaceutical industry profit motives by noting, "I think part of the problem with over-prescribing is that the drug companies are making money off of it." One African-American participant, on the other hand, told a lengthy story about feeling frustrated after realizing he could save money by informing providers not to duplicate a medical test he recently received elsewhere; he wondered why doctors did not provide that information to him. Another African-American participant responded, "You got to think, doctors are there to help, yes. But it's also a thing of money, just like us... we go to the beauty parlor. She ain't going to tell you if you wash your hair before you come, that's cheaper. She want to wash your hair and everything."

Cost Drivers. As deliberation continued, discussions explored perceived relationships between health care system profit motives and rising costs. One participant noted, "It's all about money. It's about pushing new meds, using patients as guinea pigs." Another participant concluded: "The United States is... driven by greed by the powers that be, and that's the underlying issue... Health is not the bottom line... for those in power to make the difference." Although profit motives were the primary driver cited for rising costs, participants also suggested other reasons, noting that doctors might recommend unnecessary tests when practicing "defensive medicine" as protection from lawsuits, for example, and that people who engage in unhealthy behaviors (e.g., smoking) drive up costs and premiums for everyone in an insurance plan when they become sick. Other participants explained that costs rise as patients use unnecessary services and because insurers, not patients, pay the majority of expenses.

Requests for Price Transparency. As discussions moved to focus on solutions, participants generally supported policies

Table 3 Attitudes toward Considering Cost in Health Care Decision-Making Pre- and Post-Deliberation*

\begin{tabular}{|c|c|c|c|c|}
\hline Outcome & Group & $\begin{array}{l}\text { Weighted } \\
\text { Pre-Mean }\end{array}$ & $\begin{array}{l}\text { Weighted } \\
\text { Post-Mean }\end{array}$ & $\begin{array}{l}\text { Adjusted Difference in } \\
\text { Pre-Post Changes }(\beta)^{\dagger}\end{array}$ \\
\hline $\begin{array}{l}\text { Doctors and patients should consider cost evidence when making } \\
\text { treatment decisions (summary score across three items) } \\
\text { People should consider the effect on group premiums when making } \\
\text { treatment decisions (single item) }\end{array}$ & $\begin{array}{l}\text { Control } \\
\text { Citizens' Panel } \\
\text { Control } \\
\text { Citizens' Panel }\end{array}$ & $\begin{array}{l}2.5 \\
2.5 \\
2.8 \\
2.7\end{array}$ & $\begin{array}{l}2.6 \\
3.2 \\
2.9 \\
3.3\end{array}$ & $\begin{array}{l}\overline{0} \\
\overline{0} \\
0.49^{\ddagger}\end{array}$ \\
\hline
\end{tabular}

*Higher scores indicate greater agreement with the outcome measure

'The $\beta$ estimate is the difference between the pre-post change for the Citizens' Panel groups and the pre-post change for the control group obtained from the analysis of covariance

${ }^{*} p<0.01$ 
that increased consistency and transparency in medical pricing. They cited the need to "create consistency in boundaries on costs to all providers... everybody has the same price for the same procedure." One participant described an idea for a website that would publicly display medical cost and evidence information: "Have one website that's open to physicians and the public that has all the research on it-one database that covers all the costs, all the procedures, all the research." With this transparency, participants generally thought patients would choose costeffective options.

\section{Reducing Costs Cited as a Rationale for Setting Boundaries.}

When asked about setting boundaries based on medical evidence, participants wanted to retain personal choice and were reluctant to set boundaries. They grappled with the fact that seemingly individual choices (e.g., smoking) can affect everyone in a health insurance plan as premiums rise. One participant questioned, "We all make choices every day that could cost all of us money...But can I tell you that you can't smoke because I don't want to pay for your treatment?" Participants did not want to limit individual choice, but also did not want to pay for others' poor choices. However, after grappling with patient/doctor autonomy and how to control costs, participants thought that the goal of reducing costs was an acceptable justification for society to set some boundaries on care. Participants largely concluded that payers have the "right" to set some boundaries on health care choice because they absorb the majority of costs. One participant explained:

"Society... should be able to set some limits because they are paying for it... so we have to do the best that we can for each individual and there has to be limits. Some people [in the discussion group] had concerns with what... those limits are. For instance, would a child end up dropping dead because limits were set on him and he didn't receive the health care that was necessary? ... There is over-testing and over-diagnosis, and what we learned up here is that somewhere our system is broken."

In general, participants who supported setting boundaries also believed that patients who desired unnecessary care should be able to pay for such care out-of-pocket. However, a common theme among African-American participants was that forcing patients to pay out-of-pocket for treatments deemed unnecessary was unfair to poor people, who would not be able to access this care. One participant argued that "the homeless and the poor can't pay for it... and I believe in helping the poor and needy." Despite this counter-perspective, many participants (including some African Americans) agreed that patients should pay out-of-pocket for unnecessary treatments, because it mirrors how society works more broadly (e.g., wealthy people have more choice when purchasing most commodities). Additionally, participants desired flexible boundaries that allowed patients to appeal decisions perceived as unfair, such as insurance companies denying coverage for treatments that doctors deem necessary.

Although participants reluctantly agreed that boundaries were necessary to reduce spending, they were mistrustful of entities with boundary-setting power, such as health insurance companies. Participants worried that these entities might set unethical boundaries (e.g., only covering inexpensive treatments that are not the highest-quality options). However, participants were slightly more comfortable with boundaries if they could be assured that the goals were to lower costs and improve quality. Participants at times argued that consumers should be informed about why decision-makers set boundaries and that decision-makers should consider diverse perspectives.

\section{DISCUSSION}

Our findings suggest that individuals may be receptive to cost containment efforts when they are informed of the rationale for such decisions (e.g., via transparent communication). Individuals may be particularly receptive if they can be assured that the ultimate goal is to improve value. We found that after deliberation, CP participants were significantly more likely than control group participants to agree that doctors and patients should consider cost evidence when making treatment decisions, and that individuals should consider the effect on group premiums when making decisions regarding treatment. Qualitative analysis provided insight into how attitudes toward cost may have shifted as participants engaged in deliberation. Participants were mistrustful of health care system profit motives and viewed these as a primary cost driver. Despite this mistrust, participants generally concluded - after grappling with patient/doctor autonomy and learning about and discussing costs during deliberation - that payers have the right to set some boundaries to curb societal costs. Participants were cautious about using evidence for cost-specific boundary setting given their mistrust of entities with the power to set boundaries and their desire for individual autonomy to choose treatments. This finding mirrors previous research highlighting public resistance to the allocation of resources or mandating treatment choices based on comparative- and costeffectiveness research. ${ }^{19,20}$ Similarly, other studies have shown public preference for patients and doctors specifically $n o t$ to consider cost in their decision-making. ${ }^{21,22}$ In addition, previous research has led to calls for better public understanding of how medical decisions affect other parties (e.g., insurers), as individuals may not recognize the role they play in rising costs. ${ }^{23,24}$ Nonetheless, grappling with the issue of rising costs during deliberation may have shifted participants' attitudes regarding this topic, as they considered how individual doctors and patients contribute to societal costs (e.g., rising insurance premiums for others).

Our qualitative analysis found that African-American participants largely expressed mistrust by describing specific 
experiences, and at times pushed back on the larger group perspective that people should pay more for unnecessary care as that policy seemed unfair to poor people. Similarly, previous research has shown that African Americans are more mistrustful than other races, perhaps given their experiences with discrimination and systematic maltreatment. ${ }^{25-27}$ Furthermore, results from the larger study showed that African Americans were less likely to agree before deliberation that doctors and patients should consider cost when making decisions, and also had significantly smaller changes in attitude regarding this outcome after deliberation compared with others. ${ }^{10}$ Accordingly, African Americans may have more strongly mistrusted the process by which health systems could deem treatments unnecessary and worried that decisionmakers could deny treatment to individuals based on race or socioeconomic status under the façade of using evidence to decide what care is unnecessary. Future research should explore race-related differences in mistrust stemming from concerns about health care costs and access.

Previous research also reveals that trust is multidimensional, and two dimensions - competence and values - may be particularly important in health care. ${ }^{28,29}$ Trust may require that patients believe that providers and systems have the competence, or technical skills, necessary to provide care and that these entities want to meet patient needs (values congruence). Our study suggests that participants mistrusted health care system values (e.g., that systems prioritize money over patient needs), highlighting the importance of considering public perceptions of decision-makers' motives in efforts to improve health care value. Future research should explore whether certain dimensions of trust, such as values, are particularly important to consider when communicating about cost-related policies.

Participants also cited transparency of cost and quality information as a necessary facilitator of informed decision-making. Without transparency, efforts to improve value may inadvertently exacerbate mistrust. Furthermore, when publicly reported cost and quality information exists, it is important to ensure that the public is aware of and able to use this information, as the use of these reports may be limited..$^{30}$ One potential strategy is to enlist support from patient navigators (who help patients navigate the health care system) and community health workers (CHWs, who may help patients change their behavior and advocate for patient concerns) in efforts to educate patients about costs and publicly reported information. ${ }^{31-34}$ Engaging patient navigators and CHWs who are trusted community members and undertaking measures to increase overall cost transparency may help to engender and earn public trust. ${ }^{33}$ Future work should explore opportunities to apply recommendations/implications from previous research toward implementing patient navigator and CHW programs on a larger scale. ${ }^{31-36}$

This study has important limitations. First, although we did not draw a nationally representative sample, we selected locations that allowed us to recruit participants from the types of areas where most Americans live (i.e., in urban areas and smaller cities accessible from nearby rural areas), and recruited a sample that matched the U.S. Census distribution in each location on several demographics. Second, we did not recruit participants without internet access. However, participants with limited internet access were included, and previous research suggests that most U.S. households have internet access. ${ }^{37}$ Third, no survey questions directly assessed participant attitudes about profit motives as a source of medical mistrust, although the survey questions provided a contextual view of how concerns about costs might have influenced discussions. It was also beyond the scope of this project to determine which specific aspects of deliberation (e.g., expert interactions) facilitated attitude shifts.

Additionally, given the intensity of $\mathrm{CP}$, sponsors may not have resources to use this method, and some individuals may not have time to participate. However, sponsors can use previous research results to weigh their needs and potential tradeoffs when considering shorter and/or online deliberative methods that require fewer resources. ${ }^{9}$

This study explored intersections between public mistrust of the health care system and perceptions of health care costs. Participants' mistrust was linked to perceptions that health care system profit motives may take priority over patient needs. However, results suggest that despite their mistrust, individuals who are informed about costs may be receptive to boundary-setting efforts to improve health care value. Decision-makers must aim to develop transparent costreduction policies to avoid exacerbating patient mistrust.

Prior Presentations: This paper has not been presented at any conferences.

Corresponding Author: Jennifer Richmond, MSPH; Domestic Research and Evaluation American Institutes for Research, Chapel Hill, NC, USA (e-mail: jrichmond@air.org).

Contributors: The authors thank their project team for their expertise and input, Joanna Siegel for her guidance as the Project Officer on the original contract, Clare Barrington for supporting the qualitative analysis, and Jessica Fernandez for helping to organize the qualitative data for analysis. The authors are indebted to participants in the Community Forum Deliberative Methods Demonstration, who taught each other and the authors so much

Funders: This study was supported by the Agency for Healthcare Research and Quality (contract no. 290-2010-00005CAHRQ). Support for Jennifer Richmond was provided by a grant from the Robert Wood Johnson Foundation Health Policy Research Scholars program (grant no. 73921). Wizdom Powell is currently supported by the National Institute on Drug Abuse (grant no. 1 KO1 DA032611-01A1). The content of this paper is solely the responsibility of the authors and does not represent the official views of the funding agencies and organizations.

\section{Compliance with Ethical Standards:}

Conflict of Interest: The authors declare that they have no conflict of interest.

\section{REFERENCES}

1. Berwick DM, Hackbarth AD. Eliminating waste in US health care. JAMA 2012;307(14):1513-6. https://doi.org/10.1001/jama.2012.362.

2. Armstrong $\mathbf{K}$, Rose A, Peters N, Long JA, McMurphy S, Shea JA. Distrust of the health care system and self-reported health in the United 
States. J Gen Intern Med 2006;21(4):292-7. https://doi.org/10.1111/j. 1525-1497.2006.00396.x.

3. Blendon RJ, Benson JM, Hero JO. Public trust in physicians-U.S. medicine in international perspective. N Engl J Med 2014;371(17):15702. https://doi.org/10.1056/NEJMp1407373.

4. Hammond WP, Matthews D, Mohottige D, Agyemang A, Corbie-Smith G. Masculinity, medical mistrust, and preventive health services delays among community-dwelling African-American men. J Gen Intern Med 2010;25(12):1300-8. https://doi.org/10.1007/s11606-010-1481-z.

5. LaVeist TA, Isaac LA, Williams KP. Mistrust of health care organizations is associated with underutilization of health services. Health Serv Res 2009;44(6):2093-105. https://doi.org/10.1111/j.1475-6773.2009.01017.x.

6. Kannan VD, Veazie PJ. Predictors of avoiding medical care and reasons for avoidance behavior. Med Care 2014;52(4):336-45. https://doi.org/10. $1097 / \mathrm{mlr} .0000000000000100$.

7. Boivin A, Lehoux P, Lacombe R, Burgers J, Grol R. Involving patients in setting priorities for healthcare improvement: a cluster randomized trial. Implement Sci 2014;9:24. https://doi.org/10.1186/1748-5908-9-24.

8. Abelson J, Forest P-G, Eyles J, Smith P, Martin E, Gauvin F-P. Deliberations about deliberative methods: issues in the design and evaluation of public participation processes. Soc Sci Med. 2003;57(2):239-51. https://doi.org/10.1016/S0277-9536(02)00343-X.

9. Carman KL, Maurer M, Mallery C, et al. Community Forum Deliberative Methods Demonstration: evaluating effectiveness and eliciting public views on use of evidence Rockville: Agency for Healthcare Research and Quality; 2014.

10. Wang G, Gold M, Siegel J, et al. Deliberation: obtaining informed input from a diverse public. J Health Care Poor Underserved 2015;26(1):22342. https://doi.org/10.1353/hpu.2015.0021.

11. Carman KL, Mallery C, Maurer M, et al. Effectiveness of public deliberation methods for gathering input on issues in healthcare: results from a randomized trial. Soc Sci Med 2015;133:11-20. https://doi.org/ 10.1016/j.socscimed.2015.03.024.

12. Maurer M, Mangrum R, Carman KL, et al. Setting boundaries: public views on limiting patient and physician autonomy in health care decisions. J Health Polit Policy Law. 2017. https://doi.org/10.1215/ 03616878-3856079.

13. Carman KL, Maurer M, Mangrum R, et al. Understanding an informed public's views on the role of evidence in making health care decisions. Health Aff (Millwood). 2016;35(4):566-74. https://doi.org/10.1377/ hlthaff.2015.1112.

14. Carman KL, Heeringa JW, Heil SKR, et al. The use of public deliberation in eliciting public input: findings from a literature review. Rockville: Agency for Healthcare Research and Quality; 2013.

15. Hsieh H-F, Shannon SE. Three Approaches to Qualitative Content Analysis. Qual Health Res 2005;15(9):1277-88. https://doi.org/10. $1177 / 1049732305276687$.

16. Ryan GW, Bernard HR. Techniques to identify themes. Field Methods 2003; 15(1):85-109.

17. Fetters MD, Curry LA, Creswell Jw. Achieving Integration in Mixed Methods Designs-Principles and Practices. Health Serv Res 2013;48(6 Pt 2):2134-56. https://doi.org/10.1111/1475-6773.12117.

18. Miles M, Huberman A. Qualitative data analysis: an expanded sourcebook. 2nd ed. Thousand Oaks: Sage Publications; 1994.

19. Gerber AS, Patashnik EM, Doherty D, Dowling C. The public wants information, not board mandates, from comparative effectiveness research. Health Aff (Millwood). 2010;29(10):1872-81. https://doi.org/10. 1377/hlthaff.2010.0655.

20. Botta MD, Blendon RJ, Benson JM. Cost-effectiveness decision making and US public opinion. JAMA Intern Med 2014;174(1):141-3. https:// doi.org/10.1001/jamainternmed.2013.11332.
21. Sommers R, Goold SD, McGlynn EA, Pearson SD, Danis M. Focus groups highlight that many patients object to clinicians' focusing on costs. Health Aff (Millwood) 2013;32(2):338-46. https://doi.org/10. 1377 /hlthaff.2012.0686.

22. Bullock AJ, Hofstatter EW, Yushak ML, Buss MK. Understanding Patients' Attitudes Toward Communication About the Cost of Cancer Care. J Oncol Pract 2012;8(4):e50-e8. https://doi.org/10.1200/JOP. 2011.000418.

23. Blendon RJ, Brodie M, Benson JM, Altman DE, Buhr T. Americans' Views of Health Care Costs, Access, and Quality. Milbank Q 2006;84(4):623-57. https://doi.org/10.1111/j.1468-0009.2006.00463.x.

24. Danis M, Sommers $\mathbf{R}$, Logan $\mathbf{J}$, et al. Exploring Public Attitudes Towards Approaches to Discussing Costs in the Clinical Encounter. J Gen Intern Med 2014;29(1):223-9. https://doi.org/10.1007/s11606013-2543-9.

25. Armstrong K, McMurphy S, Dean LT, et al. Differences in the patterns of health care system distrust between blacks and whites. J Gen Intern Med 2008;23(6):827-33. https://doi.org/10.1007/s11606-008-0561-9.

26. Armstrong $\mathbf{K}$, Putt $\mathbf{M}$, Halbert $\mathbf{C H}$, et al. Prior experiences of racial discrimination and racial differences in health care system distrust. Med Care 2013;51(2):144-50. https://doi.org/10.1097/MLR. Ob013e31827310al.

27. Martin KD, Roter DL, Beach MC, Carson KA, Cooper LA. Physician communication behaviors and trust among black and white patients with hypertension. Med Care 2013;51(2):151-7. https://doi.org/10.1097/ MLR.Ob013e31827632a2.

28. Shea JA, Micco E, Dean LT, McMurphy S, Schwartz JS, Armstrong K. Development of a revised Health Care System Distrust scale. J Gen Intern Med 2008;23(6):727-32. https://doi.org/10.1007/s11606-008-0575-3.

29. Armstrong $\mathbf{K}$, Putt $\mathbf{M}$, Halbert $\mathbf{C H}$, et al. The influence of health care policies and health care system distrust on willingness to undergo genetic testing. Med Care 2012;50(5):381-7. https://doi.org/10.1097/MLR. Ob013e31824d748b.

30. Greene J, Fuentes-Caceres V, Verevkina N, Shi Y. Who's aware of and using public reports of provider quality? J Health Care Poor Underserved 2015;26(3):873-88. https://doi.org/10.1353/hpu.2015.0093.

31. Shah MK, Heisler M, Davis MM. Community health workers and the Patient Protection and Affordable Care Act: an opportunity for a research, advocacy, and policy agenda. J Health Care Poor Underserved 2014;25(1):17-24. https://doi.org/10.1353/hpu.2014.0019.

32. Martinez J, Ro M, Villa NW, Powell W, Knickman JR. Transforming the delivery of care in the post-health reform era: what role will community health workers play? Am J Public Health 2011;101(12):e1-5. https://doi. org/10.2105/ajph.2011.300335.

33. Natale-Pereira A, Enard KR, Nevarez L, Jones LA. The role of patient navigators in eliminating health disparities. Cancer 2011;117(15 Suppl):3543-52. https://doi.org/10.1002/cncr.26264.

34. Viswanathan M, Kraschnewski JL, Nishikawa B, et al. Outcomes and costs of community health worker interventions: a systematic review. Med Care 2010:792-808.

35. Perry H, Crigler L, Lewin S, Glenton C, LeBan K, Hodgins S. A new resource for developing and strengthening large-scale community health worker programs. Hum Resour Health 2017;15(1):13. https://doi.org/ 10.1186/s12960-016-0178-8.

36. Valaitis RK, Carter N, Lam A, Nicholl J, Feather J, Cleghorn L. Implementation and maintenance of patient navigation programs linking primary care with community-based health and social services: a scoping literature review. BMC Health Serv Res 2017;17(1):116. https://doi.org/ 10.1186/s12913-017-2046-1.

37. File T, Ryan C. Computer and Internet use in the United States: 2013. American Community Survey Reports. 2014 